\title{
Amistad en letras de molde: reconstrucción de una red social femenina a partir de las memorias de Maria Mancini (1677)*
}

\section{Friendship in Block Letters: Reconstruction of a Women's Social Network through Maria Mancini’s Memoirs (1677)}

\author{
Gabriela Martínez Pérez \\ UNED \\ gabrielamartinez@flog.uned.es \\ ORCID iD: http://orcid.org/0000-0001-5473-3144
}

\section{RESUMEN}

El presente artículo trata de reconstruir las relaciones entre varias mujeres que participaron de formas diferentes en libros publicados en las últimas décadas del siglo XVII: como dedicatarias, autoras, mecenas o simplemente como personajes a los que se menciona en ellos. Partiendo de las memorias que Maria Mancini publica en 1677, se realiza un recorrido por la información extraída fundamentalmente de paratextos de la época mediante la cual trata de definirse qué tipo de red constituían estas mujeres, qué tipo de relaciones establecían entre sí y con otros agentes del campo literario y qué modelos femeninos emanaban de su actividad en torno a los impresos en la época.

Palabras Clave: mujeres; redes sociales; paratextos; siglo XVII.

\section{ABSTRACT}

This paper aims to depict the connections among a group of women who took part in different ways in books published by the last decades of the 17th century, being dedicatees, authors, patronesses or just characters mentioned in them. Starting with the memoirs published by Maria Mancini in 1677 , a tour through data extracted essentially from paratexts is taken in order to define which kind of links had they established both among themselves and with other agents of the literary field and what female models emerged from their activity around the contemporary publications.

Key words: Women; Social Networks; Paratexts; 17th Century.

* Este trabajo se halla vinculado al proyecto Escritoras españolas de la primera modernidad: metadatos, visualización y análisis (ref. FFI2015-70548-P) y fue realizado durante el disfrute de un contrato predoctoral para la formación de doctores (ref. BES-2016076676) cofinanciado por la Agencia Estatal de Investigación y el Fondo Social Europeo, en el marco de dicho proyecto. 
La autobiografía religiosa es uno de los géneros de escritura femenina más prolíficos del periodo premoderno hispano, con cifras que resultan muy abultadas en ese panorama - cerca de trescientas obras-, un prodigio que se debe enteramente a que la Vida de Santa Teresa resultó un ejemplo de extraordinaria fecundidad $^{1}$. En contraposición con este llamativo fenómeno, la búsqueda de autobiografías de mujeres seglares en el Siglo de Oro es una labor prácticamente imposible. Como apunta Nieves Baranda (2014), para encontrar un número algo significativo -aunque igualmente muy exiguo- de documentos en los que mujeres no religiosas se dispongan a realizar un relato de su devenir vital, es necesario ampliar los márgenes de la búsqueda y tomar en consideración no solo libros impresos, sino textos bajo formas diferentes y no siempre de carácter público: «pueden ser desde una carta a una dedicatoria, un documento legal, parte de una crónica o una relación pública» (Baranda 2014, 25).

Dadas las características del contexto, las memorias de la italo-francesa Maria Mancini (Zaragoza, 1677), publicadas bajo el título La verdad en su luz, emergen como un extraño objeto libresco en el entorno editorial del XVII. La obra es, pues, una excepción, pero lo cierto es que no menos excepcionales son las circunstancias vitales de la autora ${ }^{2}$. Mancini nace en Italia en 1639 pero se traslada a los pocos años a la corte francesa con su tío, el cardenal Mazarino, donde recibe una excelente educación: se relaciona con el círculo de Ana de Austria y termina por conformase como una más de las preciosas francesas. Además, allí inicia una relación sentimental con el futuro Luis XIV, un hecho que la marcaría tanto personalmente como en su imagen pública en la corte. Finalmente, la etapa francesa de Mancini se cierra en 1661 con su matrimonio con el poderoso Lorenzo Onofrio Colonna -miembro de una de las más ilustres familias italianas, príncipe de Paliano y condestable de Nápoles-, lo que supone su traslado a Roma. Tras años de matrimonio y vida familiar, Mancini se decide a abandonar su casa y a su esposo y en mayo de 1672 emprende una huida por varios países europeos ante el asombro de sus contemporáneos. El periplo finalizará cuando, dos años más tarde de su inicio, sea cautivada por los hombres de su marido y trasladada a Madrid, donde se la obligará a vivir tras las rejas del convento de Santo Domingo el Real con la intención de salvaguardar su honra y la del condestable. Desde allí escribe sus memorias en francés ( $L a$ vérité dans son jour), que serán traducidas al español por Pablo Billet ${ }^{3}$ y bajo supervisión de la autora y publicadas, como se ha señalado, en 1677.

1 Para un panorama general sobre la autobiografía religiosa femenina se pueden consultar Poutrin 1995; Herpoel 1999; Durán 2007.

${ }^{2}$ La biografía de Mancini ha sido abordada por múltiples autores, pueden verse, por ejemplo, Doscot (1987, 24-28), Dulong (1993) o Cholakian (2000, 101-121).

3 Sobre la cuestión de las ediciones del texto y las dudas en torno a la publicación que se mencionarán más adelante, ver Martínez Pérez (2019). 
La verdad en su luz es un libro de carácter autobiográfico que, sin embargo, no nace de la mera la voluntad de la autora de dejar constancia de su vida, sino como un ejercicio de propaganda personal en, al menos, dos sentidos. En primer lugar, para combatir la publicación de unas falsas memorias (Anónimo 1676) que se habían publicado un año antes en su nombre y cuyo contenido resultaba inaceptable para Mancini por cuanto ponían en cuestión su honra y desprestigiaban su imagen pública ${ }^{4}$. Por otro lado, y vinculado a lo anterior, para justificar sus actos y particularmente la decisión de abandonar a su esposo y sus hijos. La publicación del libro, así, le daría la posibilidad a su autora de lograr el respaldo de sus coetáneos, y fundamentalmente de los reyes, quienes podrían interceder por ella ante el condestable Colonna para que le permitiese abandonar el convento y retomar su vida cortesana en Madrid con libertad ${ }^{5}$.

Teniendo en cuenta lo apuntado hasta el momento, entender la publicación de este libro en los términos que propone Bourdieu ${ }^{6}$ como una toma de posición simultánea en el campo cultural y el del poder es necesario para comprender su verdadero alcance. Como el sociólogo francés apunta, «... debido al juego de las homologías entre el campo literario y el campo del poder o el campo social en su conjunto, la mayoría de las estrategias literarias están sobredeterminadas y muchas de sus "elecciones" son golpes dobles, a la vez estéticos y políticos, internos y externos» (Bourdieu 2015, 307-308). Con la publicación de La verdad en su luz, Maria Mancini busca inscribirse en el campo a la vez como dama de conducta ejemplar frente a los rumores y como mujer culta, capaz de emplear la escritura para definir sus propias estrategias de legitimación. En este sentido, y en consonancia con la cita de Bourdieu, no se debe pasar por alto la elección formal del género de las memorias, que apunta a una larga tradición (fundamentalmente masculina) de grandes figuras que consideraron su vida digna de ser transmitida a futuras generaciones. A pesar de que las aspiraciones de Mancini sean mucho más inmediatas, ella no deja de escribir un texto conforme a unas pautas genéricas que fijan el horizonte de lectura $y$, a la vez, la sitúan en la misma senda de otros personajes célebres y generalmente bien posicionados en el campo de poder, como es también su caso.

${ }^{4}$ Para desgracia de la Mancini, además, las memorias espurias parecen haber disfrutado de interés entre sus contemporáneos si se considera el número de ediciones: una en italiano y tres en francés.

${ }^{5}$ La interpelación a Carlos II se hace explícita en las últimas líneas de las memorias: «... estoy ahora, esperando ordene su Majestad de mi fortuna, ignorando todavía en qué ha de parar, aunque debo esperar de la benignidad y justicia de este monarca, y de la suprema prudencia de su Alteza, hallaré finalmente en lo piadoso y justo del primero y en lo prudencial del segundo, el término de mis trabajos y la quietud que deseo, con ansia y necesidad igual. FIN» (Mancini 1677, 326). Sobre las vivencias y las relaciones establecidas por Mancini en la corte de Carlos II y Mariana de Neoburgo, ver Frutos (2015) y Sobaler Seco (2016).

${ }^{6}$ Seguiré en lo sucesivo, aunque no se haga explícito, la metodología que Bourdieu desarrolla en Las reglas del arte (2015). 
Las pretensiones de la autora de estas peculiares memorias quedan claras en los primeros párrafos con los que se inicia el relato (Mancini 1677, 1-5), donde, a modo de prólogo encubierto ${ }^{7}$, se apunta la necesidad de combatir los rumores para evitar que quienes no la conozcan puedan llegar a creerlos y se insiste en la idea de que la propia autora ha mantenido a lo largo de su vida una conducta ejemplar y unos procederes escrupulosamente rectos. Por tanto, este prólogo sui generis contribuye a explicitar el marco de lectura del texto y refuerza sus ideas centrales, como viene siendo habitual en los paratextos que acompañan a las obras y que ya tantos, siguiendo la estela inaugurada por Genette (1987), han reivindicado como determinante objeto de estudio en la literatura de la Edad Moderna hispánica ${ }^{8}$. El prólogo encubierto no es el único paratexto que acompaña las memorias de Mancini ni el único que ofrece información esencial sobre el posicionamiento de esta en el campo social y cultural de su tiempo. Esos documentos, adheridos de modo aparentemente inconexo al cuerpo central del libro, permiten obtener datos que servirán para comprender qué entorno respaldó la aparición de un libro tan atípico, tanto desde el punto de vista material como de su contenido, que aspiraba a recomponer el prestigio de una figura femenina denostada.

Lo primero en lo que cabe reparar no es ya en los elementos presentes, sino en las llamativas ausencias: La verdad en su luz carece de ningún paratexto legal (privilegio, tasa, etc.). Es difícil encontrar una respuesta congruente a estas carencias en la producción académica sobre la legislación editorial en el período, pero seguramente si nos apoyamos también en el hecho de que en la portada se indica el lugar de publicación y el año (Zaragoza, 1677) y no la imprenta, podemos plantear que el libro se editase sin los permisos correspondientes con la idea de hacerlo circular esencialmente en el entorno cortesano, y podría ser que la alusión a Zaragoza constituya una mera superchería para evitar posibles sanciones legales del Reino de Castilla (Martínez Pérez, 2019).

Fuera de los legales, otros paratextos sí constan en las memorias. Además de la portada, La verdad en su luz presenta una dedicatoria a María Petronila Niño Enríquez de Guzmán, condesa de Villaumbrosa, un soneto dedicado al traductor del texto, Pablo Billet, firmado por P. Tegano y un prólogo al lector

7 Se trata de un prólogo que no es señalado tipográficamente como tal (ni mediante un titulillo, ni en página aparte), sino que constituye las primeras líneas del cuerpo de las memorias. A pesar de ello, es percibido por el lector como un prólogo tanto por el tipo de contenido que presenta - un preliminar para la lectura- como el hecho de que tras este párrafo se inicia el relato autobiográfico de manera clara: «Nací en Roma de una familia...» (Mancini 1677, 5). Este concepto es empleado por Bieses (Bibliografia de Escritoras Espanolas, http://www.bieses.net) en su proyecto de edición de paratextos de los impresos de autoras entre 1500 y 1800 .

${ }^{8}$ Como muestras indicativas y destacadas de esta tendencia, deben tomarse en cuenta el monográfico de Cayuela (1996), el volumen coordinado por Arredondo, Civil y Moner (2009), el estudio de García Aguilar (2009) y el especial de Criticón coordinado por Baranda (2015). 
del propio Billet. La portada de La verdad en su luz (Fig. 1) pone en relación ya a los tres agentes que integran la red que da lugar a la aparición del texto: autora, traductor y dedicataria, cuyas vinculaciones e intereses trataremos de poner de manifiesto a continuación.

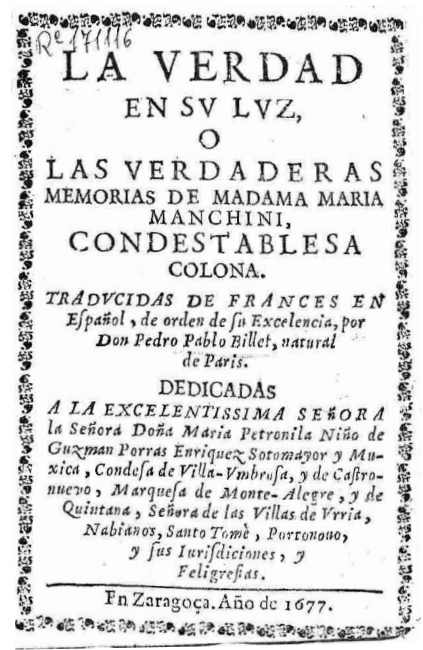

Figura 1. Portada de La verdad en su luz. Fuente: Mancini 1677.

Además de traductor, Billet es autor de la dedicatoria ${ }^{9}$ y del prólogo, en el que realiza una importante defensa de la autora incidiendo -como hemos dicho que hace también en el incipit del texto la propia Mancini- en la maldad con que se habían emitido juicios falsos contra ella y su honra de forma totalmente injusta e infundada:

Si es axioma en el derecho que la disculpa no inquirida arguye delito y se convierte en acusación manifiesta, no ignoras (cuando viene provocada con los estímulos de libelos y calumnias) que no solo es lícita, pero aún precisa. Esta consideración dio motivo a la publicación de estas memorias, como el principio de ellas lo da claramente a entender, en uno y otro idioma, y la sola necesidad de la defensa las trae hoy a su noticia. [...] No culpes severo lo que te pareciere desacierto, pues la vida más ajustada a las reglas de la prudencia no se libra de yerros; y por no incurrir en los del necio, censor inadvertido que nos inspira el sagrado texto, mira con piedad las acciones ajenas y con atención desapasionada repara las propias; no, obediente a los impulsos de nuestra naturaleza corrompida, des interpretaciones siniestras a las exterioridades; y acuérdate que hay desaciertos que más merecen advertencia compasiva que no rigurosa reprehensión, porque son más influencias de los astros que determinaciones de la voluntad (Mancini 1677, h. 3v).

9 Nos hallamos, por tanto, ante lo que Genette llama una dedicatoria alógrafa (1987, 8), si bien, como se verá, claramente mediada y aceptada por la autora. 
De Pablo Billet se apunta en la portada misma que es 'parisiense', circunstancia que supone un punto en común con Mancini, quien siempre consideró la capital francesa como su verdadera cuna. Además de su trabajo como traductor en La verdad en su luz, Billet es autor de una conocida Gramática francesa en la que se ofrecen detalles sobre los usos y el léxico pensados para el estudiante del idioma, y que ha resultado ser de interés en el estudio de la historia de la enseñanza del francés en España (Ischer 1996). En la primera edición de este texto -hubo varias- el autor indica que «... diez años, y más, que ha que profeso enseñar la nuestra [lengua] a diversos particulares, y príncipes, y la castellana a diversos señores, que de las naciones extranjeras, una peregrina curiosidad, o sus negocios trajeron a esta corte» $(1673,101)$, haciendo gala de la posesión de un capital simbólico que le vendría garantizado por su relación con la élite de la sociedad española del momento. En la misma línea de una representación encumbrada del autor se encuentra la censura que acompaña a la edición de 1708, donde quien la redacta llama a Billet «este Nebrija de la francesa gramática» (Billet 1708, h.4v).

El prestigio y la evidencia de una buena relación con quienes ostentaban unas posiciones relevantes dentro del campo de poder hacen comprender en gran parte que él fuese el elegido por Mancini para la traducción de su libro. Sin embargo, la conexión con La verdad en su luz se hace definitiva y explícita en dos de los paratextos de la Gramática. En primer lugar, en la portada: como en las memorias, aquí aparece el lugar y año de publicación (Zaragoza, 1673), pero no la imprenta; además, este libro tampoco contiene ningún paratexto de carácter legal. Esta coincidencia puede hace suponer que el papel de agente de Billet fue más allá de la traducción de la autobiografía, y no sería extraño, con estos datos en la mano, que fuese él quien gestionara la publicación alegal del texto. En segundo lugar, y de mayor interés, las memorias de Mancini y la gramática de Billet comparten dedicataria: María Petronila Niño Enríquez de Guzmán. De ella se afirma en la dedicatoria de la Gramática francesa:

Es desempeño de una obligación precisa, y volver à V. Exc. una obra que por tan justificadas razones puedo decir que es suya; pues si miro su principio, reconozco que V. Exc. me alentó a que la emprendiese, si atiendo a su progreso, debo el acierto de sus preceptos a las dudas que tan agudamente me proponía V.E. como discretamente las comprehendía (Billet 1673, h.2r-v, el subrayado es nuestro).

El fragmento parece hacer clara alusión a que Billet fue profesor de lenguas de Petronila Niño, a quien perfila como una buena alumna. El dato, además, permite barajar la idea de que esta fuese una dama con una cierta cultura. Retomemos en este punto la dedicatoria de La verdad en su luz que, como se ha dicho, está redactada por el propio Billet: 
Parecerá inadvertencia dedicar a vuestra excelencia la traducción de las memorias de la excelentísima señora condestablesa Colona, siendo vuestra excelencia tan perita en el idioma en que primero se escribieron, que dudo si vuestra excelencia sabe con más primor el suyo. Pero habiendo de salir a la luz, para desengaño de muchos y escarmiento de aquellos que con el aliento de sus murmuraciones han intentado empañar el cristal de tan inocente (aunque infeliz) vida, qué más favorables auspicios que los de vuestra excelencia y qué amparo más conforme a la grandeza del sujeto que en traje español sale hoy a la defensa y justificación de sus acciones. Y cuando no hubieran hecho precisa tan soberana elección estas circunstancias y la estrecha amistad que tiene con vuestra excelencia la excelentísima condestablesa, no me hubiera permitido consagrar en otras aras esta corta fatiga (y solo considerable por su asunto) el voto que [...] hice de poner a sus pies cuantas sacase a la luz mi corta capacidad. Espero no será esta menos feliz, pues tiene circunstancias para no ser menos del agrado de vuestra excelencia y logrará universal aplauso en la sola aprobación de vuestra excelencia... (Mancini 1677, h.1v - h.2v, el subrayado es mío).

Nuevamente, Billet incide en esta dedicatoria en la caracterización de Petronila Niño como una mujer culta a través de la referencia a su dominio del francés y, además, destaca la amistad que la une con Mancini; «estrecha amistad», para más señas. No obstante, tal vez lo más destacado del fragmento sea la explicitud de las ventajas que se obtienen de tener a aquella dama como dedicataria: «qué más favorables auspicios que los de vuestra excelencia y qué amparo más conforme a la grandeza del sujeto que en traje español sale hoy a la defensa y justificación de sus acciones». La función de la dedicataria en este caso no sería, como en otros ${ }^{10}$, la de financiar la publicación -las circunstancias económicas de Mancini no lo harían necesario-, sino la de reforzar la autorrepresentación positiva de la autora en sus memorias mediante el paralelismo que se podría establecer entre las dos mujeres. Por otra parte, si Mancini quiso dejar en su obra constancia de la amistad con doña Petronila Niño a través de la mano de Billet, con la idea de que la certificación pública de un vínculo entre ambas sería positiva para su propia imagen, cabe preguntarse cuál era la

10 Sobre el papel de los dedicatarios como agentes en la publicación de libros deben tenerse en cuenta las precisiones de Jaime Moll, aunque hoy se trabaja con perspectivas menos bilaterales y economicistas, como se verá en este trabajo: «Si el libro es fruto de una técnica, también es un producto fabricado. Ello exige una inversión: papel y pago de la impresión. Algunos autores pueden pagar estos gastos, sobre todo cuando se trata de pequeños libros. En algunos casos, un protector del escritor puede financiar la edición. Debo señalar que, a mi parecer, se ha abusado al considerar como mecenas las personas a quienes se dedica un libro [...]. Son pocas las ocasiones en que los llamados mecenas financian una edición. El interés del autor en la persona a quien dedica públicamente la obra puede ser de agradecimiento de algún favor recibido, pretensión de recibirlo, en algún caso espera de un obsequio, prueba de amistad, etc., y también, establecida la costumbre, una manera de enaltecer el libro con el nombre de la persona a quien va dedicado, sin olvidar la prestancia dada a la portada por su blasón» (Moll 1982, 46). 
posición que la propia Petronila ocupaba en el campo de poder y en el cultural de su tiempo y qué motivos podían propiciar la relación entre ambas.

Además de las dos dedicatorias escritas por Billet que hemos referido, doña Petronila Niño Enríquez de Guzmán dejó otros testimonios de sus intereses culturales y de su privilegiada posición social. La condesa de Villaumbrosa nació en 1640 -un año después que Mancini-, murió en 1700 y contrajo matrimonio con su tío, don Pedro Núñez de Guzmán (1615-1678), marqués de Montealegre y un importante hombre de estado que ostentó los cargos de oidor de la chancillería de Valladolid, fiscal del Consejo de Indias, presidente del Consejo Real de Castilla o consejero de Estado, entre otros (Fayard 1982, 145). Sus galones políticos y sus títulos nobiliarios garantizarían la acumulación de capital social y simbólico y una situación privilegiada en el campo de poder, pero a ello habría que sumar que el marqués fue un gran bibliófilo y poseedor de una impresionante biblioteca cuyo contenido quedó registrado en un inventario publicado poco antes de su muerte (Maldonado y Pardo 1677).

La decisión de cultivar una biblioteca como esta y, más aún, la publicación de su inventario ${ }^{11}$ suponen una toma de posición del marqués bien determinada, que de este modo se exhibe como un noble docto no solo en leyes y política, sino también en artes y ciencias. En la dedicatoria al inventario, de hecho, José Maldonado y Pardo sitúa al marqués como heredero de la tradición de tantos príncipes que a lo largo de la historia hicieron acompañar su buen gobierno del interés en el saber y las letras: «... nacen obligados los príncipes grandes a saber los preceptos de todas las ciencias, juzgando preciso en tan elevados sujetos poseer cumplidamente la sabiduría, sin duda porque son instrumentos de la felicidad política y de la salud pública» (1677, h. 3v).

$\mathrm{Si}$, pues, la publicación de dicha biblioteca supone una toma de posición en el campo cultural del marqués de Montealegre, no menos lo será de su esposa Petronila $\mathrm{Niño}^{12}$, pues también para ella hay un párrafo reservado en la dedicatoria. Una vez más, como ya se había visto en las escritas por Billet, se

11 Sobre los inventarios de bibliotecas áureas, ver Infantes (1998).

12 Es importante tener en cuenta que la vinculación de la condesa de Villaumbrosa con la biblioteca de su marido no es solo supuesta, sino que existen pruebas firmes de que ella manejó al menos algunos volúmenes del conjunto. Como apunta Pedro M. Cátedra (2003, 17), mientras que de las lecturas del marqués no ha quedado huella, la condesa de Villaumbrosa sí dejó su marca en varios ejemplares, asegurando haberlos leído. Así ocurre en la Nueva filosofía de la naturaleza del hombre de Olivia Sabuco (1588, Biblioteca Nacional de España R/29790) o en Historiae Francorum scriptores coetanei... de André du Chesne (1588, Biblioteca de la Universidad de Salamanca BG/29879), en cuyas portadas se lee la siguiente anotación manuscrita: «Ego Maria Petronila Niño Enrriquez de Guzman Comitissa Ville Umbrose hunc legi librum à prima usque ad ultimam paginam». Lo mismo ocurre en el Examen de Ingenios de Huarte de San Juan (1594, Biblioteca Nacional de España $\mathrm{R} / 291$ ), que además conserva pasajes subrayados o marcados mediante pequeños dibujos de manos o dedos, como es frecuente en estos testimonios. Nieves Baranda apunta que 
hace referencia a la cultura de la mujer, en esta ocasión aún con mayor vehemencia:

De la excelentísima consorte de V. E., si hubiera de referir su erudición, estudios de matemáticas, comprensión de la filosofía, adornada de la noticia de buenas letras, y historias, con el conocimiento de los idiomas extranjeros, fuera detener mucho a V. E. y quedar siempre corto: es sin duda Minerva española (Maldonado y Pardo 1677, h. 4v).

Esta muestra, en la que la hipérbole campa a sus anchas como corresponde al contexto laudatorio en el que se encuentra, encontramos también una primera alusión a la tópica de la mujer culta, la de designar a la marquesa como «minerva» española. La idea, aplicada a esta dama, no será exclusiva del texto de Maldonado y Pardo. Además de lo apuntado hasta el momento, Petronila Niño Enríquez de Guzmán participó como agente en otras obras publicadas en la segunda mitad del XVII, en las que encontramos de nuevo muestras de su representación textual. Así, es posible encontrarla como dedicataria de, al menos, otras dos obras: la Esfera en común celeste y terráquea, de José Zaragoza (1675) y La venerable madre sor María de la Santísima Trinidad, religiosa de la tercera orden de Santo Domingo, de Fray Antonio de Lorea (1671). En la primera de estas últimas dos muestras, el libro de José Zaragoza, la dedicatoria nuevamente está dirigida a la condesa y en ella se dan cita los mismos tópicos en referencia a su condición de mujer culta que hasta ahora se había visto, insistiendo junto con ello en la nobleza de sus orígenes:

Repartieron los antiguos todas las facultades entre las nueve Musas, a quien presidía Apolo: con más razón si previeran la sobre humana comprensión de V.E. la veneraran presidenta de las nueve, o despreciando el numeroso coro, adoraran todas las ciencias en sola una deidad. No le parecerá hipérbole a quien considerase que en cuatro meses aprendió V.E. la lengua francesa, en pocos más la latina, y todas con perfección. Poco es esto para quien admira los progresos matemáticos en menos de seis meses, dejando vencidas la aritmética, geometría, esfera y astronomía, cuya inmensa altura hace ya vanidad de verse rendida al sublime ingenio de V.E. ... (Zaragoza 1675, h.2v)

A la configuración como Minerva que antes se había visto, se suma ahora la de Musa; una y otra fueron usadas con fecundidad en el Siglo de Oro para referirse a mujeres cultas ${ }^{13}$. Tomadas de la tradición clásica (fue Platón quien difundió el tópico de Safo como la décima Musa), muestras de esta práctica se

estas anotaciones, poco comunes en libros pertenecientes a mujeres, supondrían un modo simbólico de mostrar la apropiación sobre el texto por parte de la condesa $(2017 \mathrm{~b}, 68)$.

${ }^{13}$ Agradezco a M. ${ }^{a}$ Carmen Marín Pina sus apuntes respecto a los apelativos con que los autores áureos se dirigieron a mujeres cultas o escritoras que se recogen a continuación. 
encuentran ya, por ejemplo, en la dedicatoria a María de Aragón del Triunfo de las donas de Juan Rodríguez del Padrón (1441 ad quem), en la que el autor se dirige a la reina como Minerva, elogiando su erudición y empleando la analogía también con connotaciones políticas (Serrano 2012, 100-103; Peláez 2014, 337-340). Las muestras se suceden en siglos posteriores, como es el caso de Garcilaso, que tratará de Musa a la poeta napolitana Maria Cardona en su Soneto $\mathrm{XIV}^{14}$, o de Lope de Vega, que acudirá en repetidas ocasiones al mismo tópico al referirse a escritoras en su particular canon del Laurel de Apolo (1630) o en el soneto «A la décima musa, doña Bernarda Ferreira de la Cerda, señora portuguesa», incluido en sus Rimas de Tomé Burguillos (1634) ${ }^{15}$. Muchas otras muestras podrían añadirse a los ejemplos propuestos, pero lo relevante para el caso que nos ocupa es que el uso de este tipo de apelativos contribuye claramente a concebir a las destinatarias de los mismos como mujeres sabias y doctas, pero también subrayan su condición de excepcionalidad dentro de su sexo. El carácter divino de Minerva o de las musas habla precisamente de que estas mujeres destacan porque poseen un buen dominio de aspectos (la cultura o, en concreto, la escritura) que no estaban al alcance de las demás, principalmente por no tratarse estos de ámbitos abiertos a la presencia femenina. Esa es también la clara intención de cuantos dedican su libro a la condesa de Villaumbrosa: destacarla como una mujer excepcional por su erudición, poco esperable dado su sexo, a lo que acompañan también sus orígenes nobles.

A pesar de que la caracterización de Petronila Niño como mujer sabia tiene una presencia importante en los paratextos en los que aparece, en La venerable madre sor María de la Santísima Trinidad, fray Antonio de Lorea incidirá en otro aspecto fundamental en la configuración prototípica de la dama noble del XVII: su religiosidad. En este caso, en la dedicatoria -nuevamente dirigida a la condesa- el autor menciona explícitamente que la obra es un encargo de esta ilustre mujer, de quien «Sabe el mundo los favores que V.E. hizo en vida, y las obras con que después de muerta ha venerado a la venerable madre sor María de la Santísima Trinidad» (Lorea 1671, h. 3v-h. 4r). Tanto en los paratextos como en el propio relato biográfico se incluirán varias referencias a los marqueses, apuntando, por ejemplo, cómo la religiosa ayudó con sus rezos a que ellos concibiesen un hijo (Lorea 1671, 194-195) o cómo el marqués de Montealegre medió y ayudó a la construcción de un nuevo convento en Sevilla

14 «Ilustre honor del nombre de Cardona, / décima moradora del Parnaso, / a Tansillo, a Miturno, al culto Taso/ sujeto noble de inmortal corona». El Broscense, además, apostilla en sus anotaciones «Décima moradora del Parnaso. Muchos han usado esta frase, de llamar a las damas doctas, Décima Musa o Cuarta Gracia, siendo las musas nueve y las gracias tres. Y ansí lo hizo Minturno en un soneto...» (Herrera 2001, 435).

15 Sobre la inclusión canónica de escritoras en la obra de Lope de Vega, ver Martos Pérez (2017). 
fundado por la monja (Lorea 1671, 221-222) ${ }^{16}$. Además, el libro contiene en sus últimas páginas una carta -que se anuncia ya en la dedicatoria- escrita por la propia Petronila a una antigua compañera de la madre sor María, sor Ana de Santo Domingo, en la que relata cómo ella fue testigo, junto a su hermana y muy pocos privilegiados más, de la apertura del sepulcro de sor María de la Santísima Trinidad y cómo descubrieron que su cuerpo estaba incorrupto (argumento en pro de su santidad):

También me despedí de mi buena amiga, y santa Madre Trinidad. Hice abrir la caja y la hallamos tan entera, como el día en que la enterraran, y tan hermosa, que era pasmo. Esto no es pasión ni encarecimiento. Del vestido y demás ropa, había pocos pedazos (que estaban consumidos) para más calificación de la incorruptibilidad de su cuerpo. Parece lo dispuso nuestro Señor. Él sea bendito, que así honra a sus santos y que tan buen día me dio. Quitele un dedo, y le tengo con suma veneración. [...] Dios lo ha dispuesto de manera que hasta el viernes no nos vamos por haberle dado un catarro grande a mi tío, de que ha estado dos veces sangrado: pero ya está bueno y me ha dicho, que por no tener la cabeza para escribir, no responde a su carta de V.M. Que tiene muy en la memoria a la fundación y hará todo cuanto estuviere en su mano con sumo gusto y yo ofrezco lo mesmo de muy buena gana, y lo haré con la fineza que debo. V.M. me escribirá lo que tengo de hacer: y fue de mí, que por diligencia ninguna no ha de quedar $(1671,283-284)$

Esta carta, mediante la que la propia voz de la marquesa de Villaumbrosa interrumpe el relato tomando así aún más presencia, viene a reforzar la idea de que el libro es una nueva toma de posición -en este caso, ya no solo de Petronila, sino del matrimonio- que busca la promoción de sor María para que llegue a ser canonizada, marcando la contribución de los marqueses a su causa y estableciendo así una vinculación con su linaje que sería muy ventajosa en términos de promoción y de obtención de capital simbólico y prestigio ${ }^{17}$.

Fray Antonio de Lorea, pues, se convierte así también en un autor por encargo, a las órdenes de los nobles, y una pieza necesaria para el desarrollo del despliegue propagandístico de aquellos. Esta vida, no obstante, no es la única obra escrita por el dominico, ni tampoco la única que cuenta con una mujer como dedicataria ${ }^{18}$. Al menos, su David pecador: enpresas morales político cristianas

${ }^{16}$ El relato que Lorea hace de sor María permite incluirla dentro de lo que Gabriella Zarri (1990) llamó «santas vivas», es decir, religiosas que fueron veneradas en vida. La elección del personaje y su configuración en el texto muestran cómo a través de esta publicación los marqueses logran una apropiación simbólica de la santidad.

${ }^{17}$ Es también interesante plantear la visión desde el otro lado: el hecho de que se inserte la carta de doña Petronila en la obra pone de manifiesto su autoridad, entendiéndose que su voz aportará veracidad a los hechos narrados.

${ }_{18}$ Baranda (2017a) señala que es frecuente que libros de carácter religioso tengan como dedicatarias a mujeres y que probablemente esa práctica esté relacionada con el hecho de que ellas serían las principales destinatarias de este tipo de obras, con lo que desde la dedicatoria se recurriría a la identificación para invitar a la lectura. 
(1674) está dedicado a sor Ana Dorotea de Austria y su traducción del toscano de La venerable madre sor Maria Vilani, religiosa de la Orden de Santo Domingo (1672), a sor Victoria de Porcia Orozco. Me detendré momentáneamente en esta última. Si bien la dedicatoria es convencional (alaba los orígenes familiares de la destinataria, le encomienda el libro y le agradece su amparo), en este entramado que se ha venido definiendo de agentes y libros y sus vínculos dentro del campo cultural y de poder, resulta destacable el hecho de que Victoria de Porcia Orozco fuera, a la sazón, abadesa del convento de Santo Domingo en Madrid: el mismo desde el que Maria Mancini había escrito sus memorias. En La verdad en su luz encontramos una mención directa a esta religiosa y a la relación entre ambas:

Halleme a los principios con harto embarazo en este nuevo hospedaje [el convento de Santo Domingo], por no saber la lengua española, ni las costumbres del país; y si no fuera por doña Vitoria Porcia Orozco, hermana del marqués de Mortara, entonces abadesa, la cual sabe muy razonablemente la lengua italiana y es discreta en extremo, hubiera tenido malos ratos (Mancini 1677, 282).

El fragmento hace alusión a tres cuestiones que han sido definitorias tanto en las representaciones textuales de la Mancini como de la marquesa de Villaumbrosa y, ahora, de Victoria de Porcia: la buena posición social y los orígenes familiares nobles reconocibles, el elevado nivel cultural (la abadesa «sabe muy razonablemente la lengua italiana») y la relación de amistad que, al menos, queda certificada entre la Mancini y las otras dos mujeres. Sobre la francesa y sor Victoria, de hecho, Laura Oliván (2012) recoge algún dato presente en los diarios de Fernando de Harrach:

Pero quizás el sitio más inaudito para entablar conversation fuera la habitación de la abadesa del monasterio de Santo Domingo El Real y no sólo por la estrechez del lugar, tan alejado de los esparcimientos posibles en huertas y jardines, sino por la originalidad de algunos de los contertulios entre los que cabe destacar Maria Mancini [...] El 4 de octubre de 1674, Harrach [...] visitó el monasterio de Santo Domingo por vez primera; allí pudo comprobar cómo la condestablesa vivía en una casa al lado del claustro y cómo discurría su retiro con ciertas libertades amablemente permitidas por su amiga la abadesa. El Almirante acudió después, cuando el grupo entró en la habitación de sor Victoria, donde tomaron chocolate y limonada para luego entrar «ein wenig in der conversation» (Oliván 2012, 155-156).

Esta participación de las dos mujeres en la especie de improvisado salón que recoge Harrach sugiere la búsqueda de espacios de sociabilización erudita mixtos, lo que vendría a insistir en cómo estas damas nobles doctas, interesadas en el saber, aspiran a tener presencia en el campo cultural, definiendo con ello un modelo de mujer que, sin adscribirse a los dictados más reaccionarios de su tiempo ni buscar una ruptura, resultó, a juzgar por estos textos, aceptable y aceptado en su tiempo. Además, el recorrido hasta aquí trazado invita a pensar en las relaciones entre estas mujeres desde una perspectiva reticular. El concepto de red social -cuya 
aplicación al ámbito de las humanidades y, en particular, de los estudios literarios ha cobrado interés en los últimos años ${ }^{19}$ - debe entenderse, en términos generales, como un conjunto finito de actores y de relaciones definidas entre ellos (Wasserman y Faust 1994). La conceptualización reticular de los datos que hasta ahora se han presentado puede resultar rentable para nuestro caso si esta se combina con las nociones de campo de poder y cultural o, específicamente, literario, por cuanto ofrece una perspectiva de conjunto que contribuye a entender de qué modo estas mujeres se posicionaron en el escenario social de su tiempo, cómo utilizaron el medio impreso para configurar su identidad pública $\mathrm{y}$, tal vez, cómo pudo contribuir la relación entre ellas en la fijación de todas estas tomas de posición.

En el caso de Maria Mancini, la vinculación en el plano extratextual, pero sobre todo intratextual con mujeres como sor Victoria de Porcia y muy especialmente de Petronila Niño Enríquez de Guzmán, con un papel preponderante en el libro, como se ha visto, supone una clara advertencia para el lector de sus memorias. No se debe olvidar que estas son principalmente una autoapología, por lo que no es baladí el uso de la dedicataria para ofrecer al lector una guía acerca del modelo de mujer con el que desea ser asociada: mujeres que son capaces de exhibir su agencia, hacer uso de los mecanismos de propaganda propios de su tiempo e inscribirse con ello en la esfera pública sin que se cuestionen su honorabilidad, su castidad y su prestigio. La relación entre ambas, así, podría entenderse como una muestra no solo de sociabilidad, sino también de solidaridad femenina.

La condesa de Villaumbrosa, por su parte, es un actor de interés en esta red por cuanto resulta un ejemplo sistemático del hasta ahora poco estudiado patro-

19 En palabras de Paniagua, «El interés de la investigación [de las redes sociales] se centra en cómo el individuo está integrado en una estructura, en una red social en la cual los actores tienen o comparten determinados vínculos, y cómo esa estructura y esa interacción con los demás va canalizando y determinando los comportamientos» $(2012,15)$. La investigación en este campo ha sido una vía de estudio que en los últimos años ha ofrecido interesantes propuestas en el ámbito de las Humanidades y, particularmente, de los estudios literarios. En esta línea se encuentran, por ejemplo, el volumen editado por John Hinks y Catherine Feely (2016) o algunos de los trabajos aparecidos en Journal of Historical Network Research (van Vugt 2017; McShane 2018). Sobre la relación entre redes sociales y paratextos, caso que aquí nos ocupa, destaca el trabajo de Brown, Soto-Corominas y Suárez (2017), en el que se encuentra una propuesta sobre cómo la metodología de redes puede contribuir a identificar estrategias de influencia y funcionamiento de la industria del libro en el Siglo de Oro español. En un ámbito de estudio próximo, el grupo Bieses viene desarrollando un proyecto anclado en la relación entre paratextos, redes de sociabilidad y autoras premodernas que ya ha arrojado algunos resultados disponibles en su página web $<$ https://www.bieses.net/las-autoras-y-susredes-de-sociabilidad $>$. Por último, como muestra de las aplicaciones interdisciplinares de esta teoría en áreas cercanas a la estrictamente literaria, cabe destacar las propuestas de dos proyectos que trabajan con las cartas de la llamada República de las Letras: «Mapping the Republic of Letters» $<$ http://republicofletters.stanford.edu $>$ y «Cultures of Knowledge: Networking the Republic of Letters, 1550-1750»<http://www.culturesofknowledge.org>. 
nazgo femenino en el campo literario. El fenómeno debería no obstante recibir nuestra atención si tenemos en cuenta las cifras recogidas por Baranda (2017a), que apunta a la existencia de más de 400 títulos que tienen una mujer como dedicataria entre los siglos XVI-XVIII, descontando a mujeres de la realeza y la casa Habsburgo. Petronila Niño, en un ejercicio que probablemente se pueda hacer extensivo a otras mujeres nobles, hace uso de las dedicatorias como espacios donde recrear textualmente su imagen con fines promocionales ${ }^{20}$. Así, con su aparición en La verdad en su luz se vincula a algunas de las familias más poderosas de Europa (los Colonna, los Mazarino), y con su probable papel de mecenas en los casos de la obra de José Zaragoza y de fray Antonio de Lorea logra difundir su nombre y situarlo dentro de un modelo determinado que hace explícito, de un lado, su capital socio-simbólico y, del otro, sus conocimientos, tal y como queda evidenciado también en los textos de las dedicatorias.

Una vez más, el paratexto y, en particular, la dedicatoria demuestran ser un objeto de estudio de especial importancia para las publicaciones de la España temprano-moderna. Estos documentos aparentemente marginales permiten entender el contexto social en el que se gestó un texto atípico en la segunda mitad del XVII como son las memorias de Maria Mancini, remarcando el papel agencial que tanto Pablo Billet como la marquesa de Villaumbrosa tuvieron en ellas. Pero, más allá, el buscar el hilo que une este texto y esos actores con otras publicaciones y tomas de posición similares permite trazar una red social que ofrece muestras probablemente extrapolables a otros casos sobre la agencia femenina en el campo cultural y literario, las estrategias propagandísticas para el impreso a las que estas accedieron en muchos casos con las mismas intenciones que los hombres y, con ello, la constatación de que esos preliminares pudieron ser usados por nobles eruditas, bien formadas, para configurar y definir modelos femeninos alternativos al mayoritario que esas mismas muestras textuales buscaban legitimar y exhibir como prestigiosos.

\section{FUENTES}

Anónimo. 1676. Les mémoires de M.L.P.M.M. Colonne G. Connetable du Royaume de Naples. À Cologne, chez Pierre Marteau.

Billet, Pablo. 1708. Gramática francesa. Madrid: Imprenta de Juan García Infançon.

Billet, Pablo. 1673. Gramática francesa. Zaragoza: s.n.

Herrera, Fernando de. 2001. Anotaciones a la poesía de Garcilaso. Ed. Inoria Pepe y José María Reyes. Madrid: Cátedra.

${ }^{20}$ Por supuesto, aunque el matiz de género sea relevante, estos beneficios asociados al mecenazgo no son exclusivos para las mujeres. En su descripción del primer campo literario español, Carlos M. Gutiérrez apunta que el patronazgo supone una «interacción social de aristocracia e intelectualidad auspiciada por un anhelo de intercambio de capital simbólico (crematístico y de lustre social, por un lado, cultural por el otro)» $(2005,24)$. 
Lorea, Antonio de. 1671. La venerable madre sor María de la Santísima Trinidad, religiosa de la tercera orden de Santo Domingo. Madrid.

Maldonado y Pardo, José. 1677. Museo o biblioteca selecta de el Exmo. Señor Don Pedro Núñez de Guzmán... Madrid: por Julián de Paredes, en la plaçuela del Ángel.

Mancini, Maria. [1677]. La vérité dans son jour ou les véritables memoires de M. Mancini, connétable de Colonna. S.1.: s.n.

Mancini, Maria. 1677. La verdad en su luz o las verdaderas memorias de Madama Maria Manchini, condestablesa Colona, trad. de P. Billet. Zaragoza: s.n.

Zaragoza, José. 1675. Esphera en común celeste y terráquea. Madrid: s.n.

\section{BiBLIOGRAFÍA CITADA}

Arredondo, M. ${ }^{\text {a }}$ Soledad, Pierre Civil y Michel Moner, eds. 2009. Paratextos en la literatura española (siglos XV-XVIII). Madrid: Casa de Velázquez.

Baranda Leturio, Nieves. 2014. "Yo soy así y así me he construido. El poder de la voz autobiográfica femenina en la Edad Moderna hispana». Guaragao 47: 19-42.

Baranda Leturio, Nieves, dir. 2015. «Paratextos y sociedad literaria». Criticón 125, monográfico. https://doi.org/10.4000/criticon.2094

Baranda Leturio, Nieves. 2017a. «Por persona interpuesta: agencia cultural femenina en la temprana modernidad española». En Actas XVIII Coloquio internacional de la AEIHM (Asociación Española de Historia e Investigación de las Mujeres), ed. Henar Gallego y

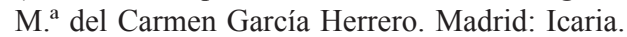

Baranda Leturio, Nieves. 2017b. Mujeres bibliófilas en España. Madrid: Turpin.

Bourdieu, Pierre. 2015. Las reglas del arte. Génesis y estructura del campo literario. Barcelona: Anagrama.

Cátedra, Pedro Manuel. 2003. «'Bibliotecas’ y libros ‘de mujeres’ en el siglo XVI». Península. Revista de Estudos Ibéricos 0: 13-27.

Cayuela, Anne. 1996. Le paratexte au Siècle d'Or : Prose romanesque, livres et lecteurs en Espagne au XVIIe siècle. Ginebra: Librairie Droz.

Cholakian, Patricia Francis. 2000. «Marie Mancini». En Women and the Politics of Self-representation in Seventeenth-century France, 101-121. Londres: Associated University Presses.

Doscot, Gérard, ed. 1987. Mémoires d'Hortense et de Marie Mancini. París: Mercure de France.

Dulong, Claude. 1993. Marie Mancini, la première passion de Louis XIV. París: Perrin.

Durán López, Fernando. 2007. Un cielo abreviado. Introducción crítica a una historia de la autobiografía religiosa en España. Madrid: Fundación Universitaria Española.

Fayard, Janine. 1982. Los miembros del Consejo de Castilla. Madrid: Siglo XXI.

Frutos, Leticia de. 2015. «Una madama francesa a la fuga: María Mancini y la corte de Madrid entre Austrias y Borbones (1674-1700)». En Los hilos de Penélope. Lealtad y fidelidades en la Monarquía de España, 1659-1714, coord. Roberto Quirós y Cristina Bravo, 241-256. Valencia: Albatros editores.

García Aguilar, Ignacio. 2009. Poesía y edición en el Siglo de Oro. Madrid: Calambur.

Genette, Gerard. 1987. Seuils. París: Seuil.

Gutiérrez, Carlos M. 2005. La espada, el rayo y la pluma: Quevedo y los campos literario $y$ de poder. Indiana: Purdue UP.

Herpoel, Sonja. 1999. A la zaga de Santa Teresa. Autobiografias por mandato. Ámsterdam: Rodopi. 
Hinks, John y Catherine Feely, eds. 2016. Historical Networks in the Book Trade. Londres - Nueva York: Routledge.

Infantes de Miguel, Víctor. 1998. "La memoria de la biblioteca: el inventario». En L'écrit dans l'Espagne du Siècle d'Or. Practiques et représentations, ed. Pedro M. Cátedra, M. ${ }^{a}$ Luisa López Vidriero y Augustin Redondo. París - Salamanca: Publications de la Sorbonne - Ediciones Universidad de Salamanca.

Ischer, Denise. 1996. «La Gramática Francesa de Pierre Paul Billet: contenus et méthodes». Documents pour l'histoire du français langue étrangère ou seconde 18: 213-223.

Martínez Pérez, Gabriela. 2019. «'Dar yo misma una relación sincera y verdadera de cuanto me ha sucedido'. Construcción identitaria y pragmatismo en las memorias de Maria Mancini (1677)». Bulletin of Hispanic Studies 96 (5): 479-493. https://doi.org/10.3828/bhs.2019.28

Martos Pérez, M. ${ }^{a}$ Dolores. 2017. «De musas a poetas: escritoras y enunciación canonizadora en la obra de Lope de Vega». Arte nuevo 4: 787-847.

McShane, Bronagh Ann. 2018. «Visualising the Reception and Circulation of Early Modern Nuns' Letters». Journal of Historical Network Research 2: 1-25.

Moll, Jaime. 1982. «El libro en el Siglo de Oro». Edad de Oro I: 43-54.

Oliván, Laura. 2012. "'Escribir un diario y una hora de baño': vidas privadas en la corte de Madrid (1650-1680)». Revista de historia moderna 30: 141-158.

Paniagua López, Juan Antonio. 2012. Curso de análisis de redes sociales. Metodología y estudios de caso. Granada: Universidad de Granada.

Peláez Flórez, Diana. 2014. «"A la más virtuossa de las mujeres”. La reina María de Aragón (1420 - 1445) como impulsora de las letras en la Corona de Castilla». Hispania LXXIV, 247: 331-356. https://doi.org/10.3989/hispania.2014.010

Poutrin, Isabelle. 1995. Le voile et la plume. Autobiographie et sainteté féminine dans l'Espagne moderne. Madrid: Casa de Velázquez.

Serrano, Florence. 2012. «Del debate a la propaganda política mediante la querella de las mujeres en Juan Rodríguez del Padrón, Diego de Valera y Álvaro de Luna». Talia Dixit 7: $97-115$.

Sobaler Seco, M. a Ángeles. 2016. «Las Memorias de María Mancini: estrategias y alianzas de una mujer en la corte de Carlos II». Tiempos modernos 33: 1-34

Soler Salcedo, Juan Miguel. 2008. Nobleza española: grandeza inmemorial, 1520. Madrid: Visión libros.

Van Vugt, Ingeborg. 2017. «Using Multi-Layered Networks to Disclose Books in the Republic of Letters». Journal of Historical Network Research 1: 25-51.

Wasserman, Stanley y Katherine Faust. 1994. Social Network Analysis. Cambridge: Cambridge University Press.

Zarri, Gabriella. 1990. Le sante vive. Profezie di corte e devozione femminile tra' 400 e '500. Turín: Rosenberg \& Sellier.

Fecha de recepción: 10 de septiembre de 2018.

Fecha de aceptación: 12 de noviembre de 2018. 